\title{
Review of solar parabolic-trough collector geometrical and thermal analyses, performance, and applications
}

\begin{abstract}
By year 2030, the world's energy demand is expected to increase by over $60 \%$ of current demand. Thus, the potential of renewable energy should be investigated. Renewable energy is the energy from natural and unnatural available forms including wind, biomass, solar, and waste heat energy generated through various human activities. Solar energy is an available and clean form of renewable energy used as an alternative to fossil fuel in generating energy. However, the maximum extraction of thermal energy from the sun is most challenging. This study focuses on energy generation using the parabolic trough collector (PTC). This review contains geometrical analysis including the thermal approach of the PTC model, heat transfer, and method of enhancing thermal efficiency on the PTC receiver. This paper also includes performance analysis, thermal efficiency, and applications of the solar-powered PTC and the history of PTC evolution. The PTC applications include desalination process, air heating system, power plants, refrigeration, and industrial heating purposes. This paper benefits researcher that focus on the solar-powered PTC.
\end{abstract}

Keyword: Parabolic trough collector; Geometry analysis; Thermal analysis; Performance; Solar energy 